\title{
TRAFFIC ASSIGNMENT MODEL OF AL-AMARAH CITY
}

\author{
Dr. Abdulhaq Hadi Abedali ${ }^{*}$ and Dr. Gofran J. QASim ${ }^{* *}$ \\ * Dept. of Highway and Transportation Eng., University of Al-Mustansiriyh-Iraq \\ ** Dept. of Highway and Transportation Eng., University of Al-Mustansiriyh-Iraq
}

\begin{abstract}
The initiation of this study was made with the objective of loading or assigning the flow of traffic in the base and target year (expressed as a matrix identifying the number of trips generated and distributed in the previous study from each Traffic analysis zone (TAZ) to every other within the study area) on a road network of Al-Amarah City.

The traffic assignment process is usually implemented in two steps. The first step is constructing the network dataset of road network of Al-Amarah city for obtaining the optimal route between each node to all other nodes depending on two criteria; distance and time for evaluation the accessibility of all nodes in the road network. The second step uses stochastic user equilibrium and system optimum assignment models to assign the traffic distributed between all possible origins and destinations to the road network itself. The analysis is done using TransCAD software ver. 4.5 and Network Analysis/Arc GIS 10.3 for Al-Amarah City.

Results showed that in the base year, The results of the stochastic user equilibrium assignment model there is no link in Al-Amarah network has v/c ratio between the range (0.81-1.00) and over which represent level of service equal to or more than D. The overall evaluation of Al-Amarah road network is level of service (LOS) equal to $B$ and there is an improvement in the work of Al-Amarah road network by using the system optimum model.

In the target year, the results of two assignment models are proximally similar. The black color (v/c $>1.0)$ is appeared clearly in the assignment result map especially on the two main bridges in the city (Al-Yugoslavi Bridge and Al-Jumhuriah Bridge). When the red color (LOS E) is appeared in the links in near the centers of sectors $(1,2$, and 4). The most links ranges between (LOS D and LOS C) with v/c ratio Range (0.70-0.90).
\end{abstract}

KEYWOARDS: Traffic Assignment Models, TransCAD, Al-Amarah city, Network Analysis.

\section{INTRODUCTION}

$\mathbf{T}$ The number of persons or vehicles per unit time that can be predicted to travel on a specific segment of a transportation system under a variety of land-use, social, economic, and environmental conditions is known as travel demand. Travel demand forecasting process predicts the number, type, source of (origin and destination of) "trips" on a transportation network (Garber and Hoel, 2010).

Al-Amarah (the capital city of Maysan Province) as many other Iraqi cities has no comprehensive published studies in transportation planning, or traffic management plans taking into account the annual growth in population, employment and car ownership, which made the performance of daily activities, represent a burden increases day after day. These reasons become necessary to prepare the transfer of detailed studies of the areas to identify the causes of these trips and then determine the origin and destination of these trips and identifies where the trips will go (Qasim G.,2016).

The traditional standard four-steps traffic demand modeling method are: trip generation, trip distribution, mode choice, and the fourth and the last phase in the travel demand modeling process is to locate the real paths of road and highway that will be utilized and the number of autos and buses that can be predicted on every highway section. The method that is utilized to set the estimated volumes of traffic is called "traffic assignment" (Haider M. and Gregoul B., 2009).

The major objectives of traffic assignment process are: predict the traffic volume on each segment of the road network and determine aggregate network measurements. Estimate the cost of travel among zones. Analyzes the pattern of travel between each pair of (O-D) zones. Recognize congested segments and to gather the necessary data of traffic for the design of future intersections (Mathew and Rao, 2007).

Travelers will choose the route which will take minimum travel time, minimum travel distance 
dependent on the traffic volume on the road (Desai T. A. et. al., 2011).

The traffic assignment process is usually implemented in two steps. The first step is constructing the network dataset of road network of Al-Amarah city for obtaining the optimal route between each node to all other nodes depending on two criteria; distance and time for evaluation the accessibility of all nodes in the road network. The second step uses stochastic user equilibrium and system optimum assignment models to assign the traffic distributed between all possible origins and destinations to the road network itself. Figure (1) shows the process used for Al-Amarah traffic assignment model.

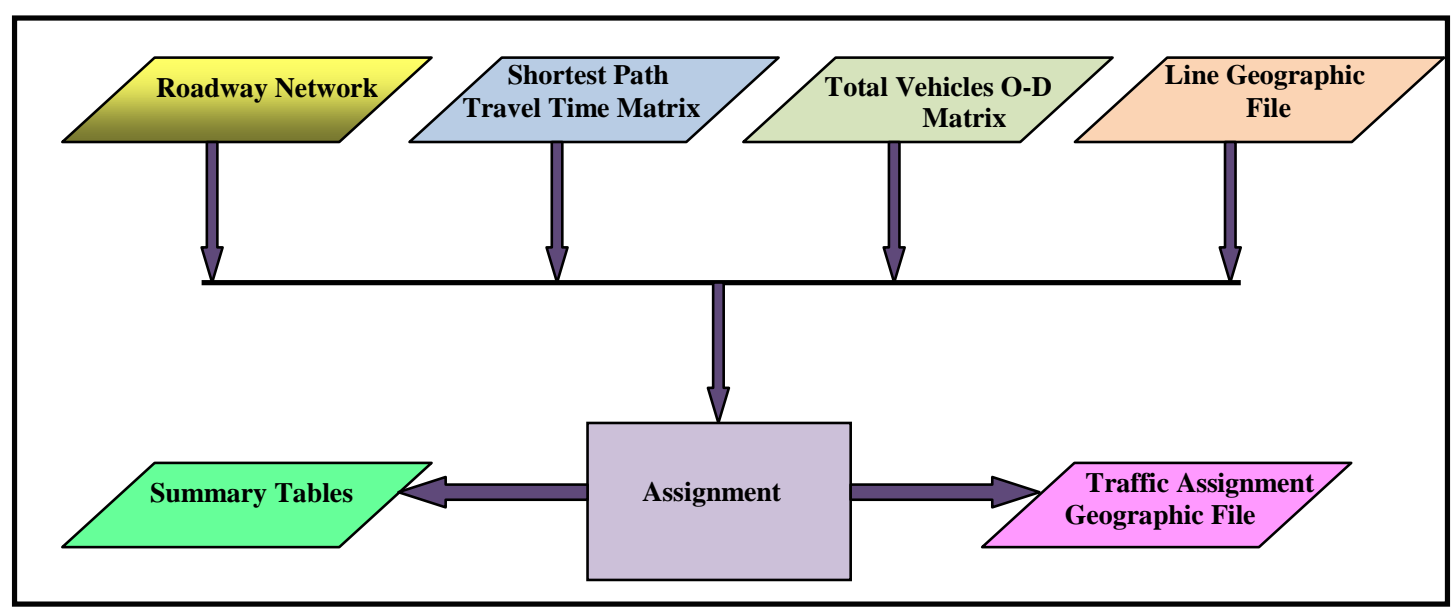

Fig.(1): Traffic Assignment Process.

\section{SHAPE FILES OF ROAD NETWORK}

To execute the traffic assignment analysis, it was necessary to prepare the shape files of the road network; these shape files were built by observing the satellite image, the master plan map of Al-Amarah city shown in the Figures (2), (3) and the collected data list.

By Arc Catalog program three shape files were built of road network, these included (links, nodes and zones or polygon). The links and bridges layer were represented as polyline feature. These shape file includes 6500 links represent the arterial, collector, and local roads, bridges and over passes of Al-Amarah city as shown in the Figure (4), Figure (5) represents the nodes and intersections layer as point feature includes 4590 nodes. The intersection has been represented by using micro representation method (number of nodes represent the conflict points in the intersection) in order to take into account the capacity and travel time of different 


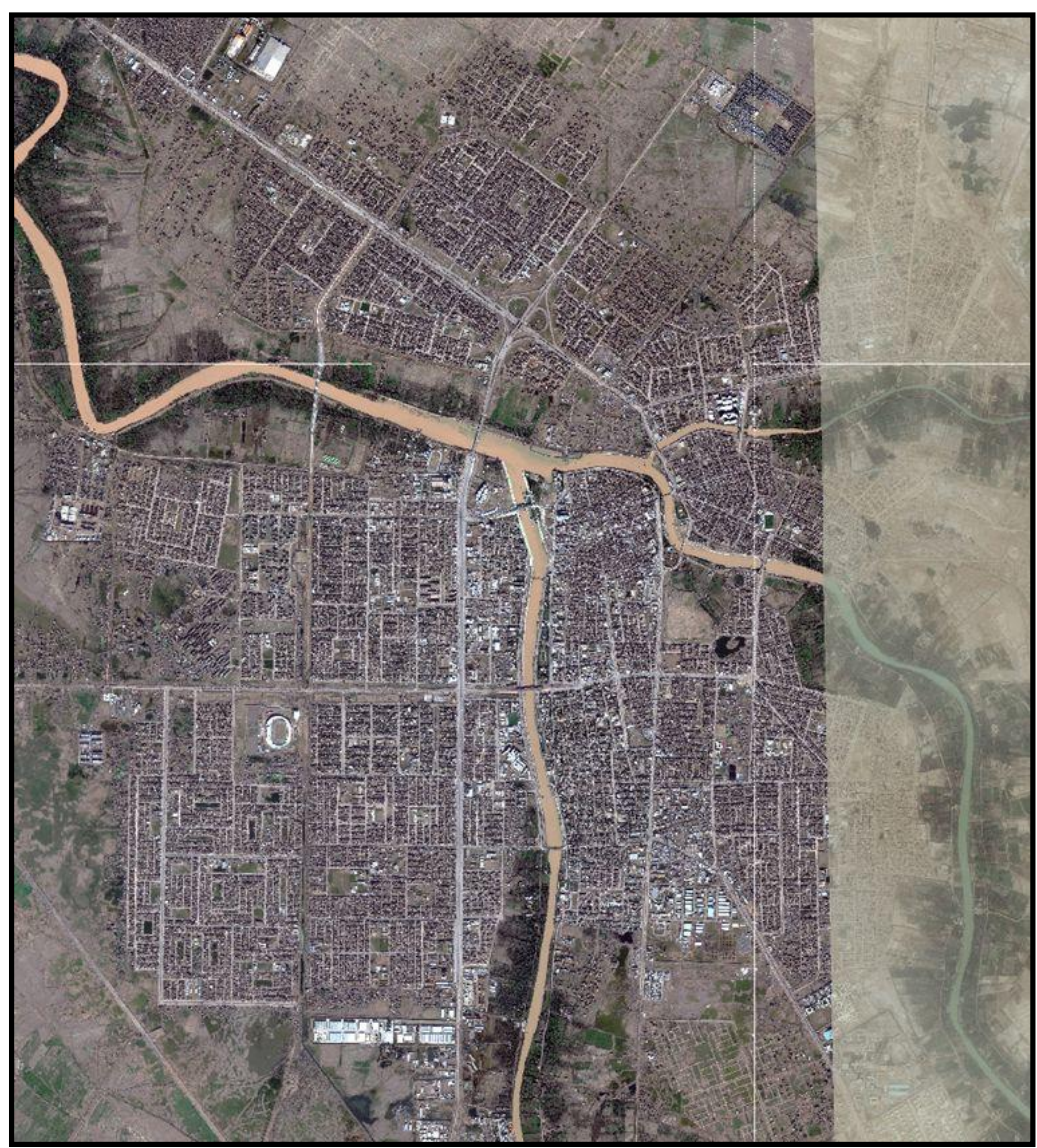

Fig. (2): Satellite Image of Al-Amarah City [2015].

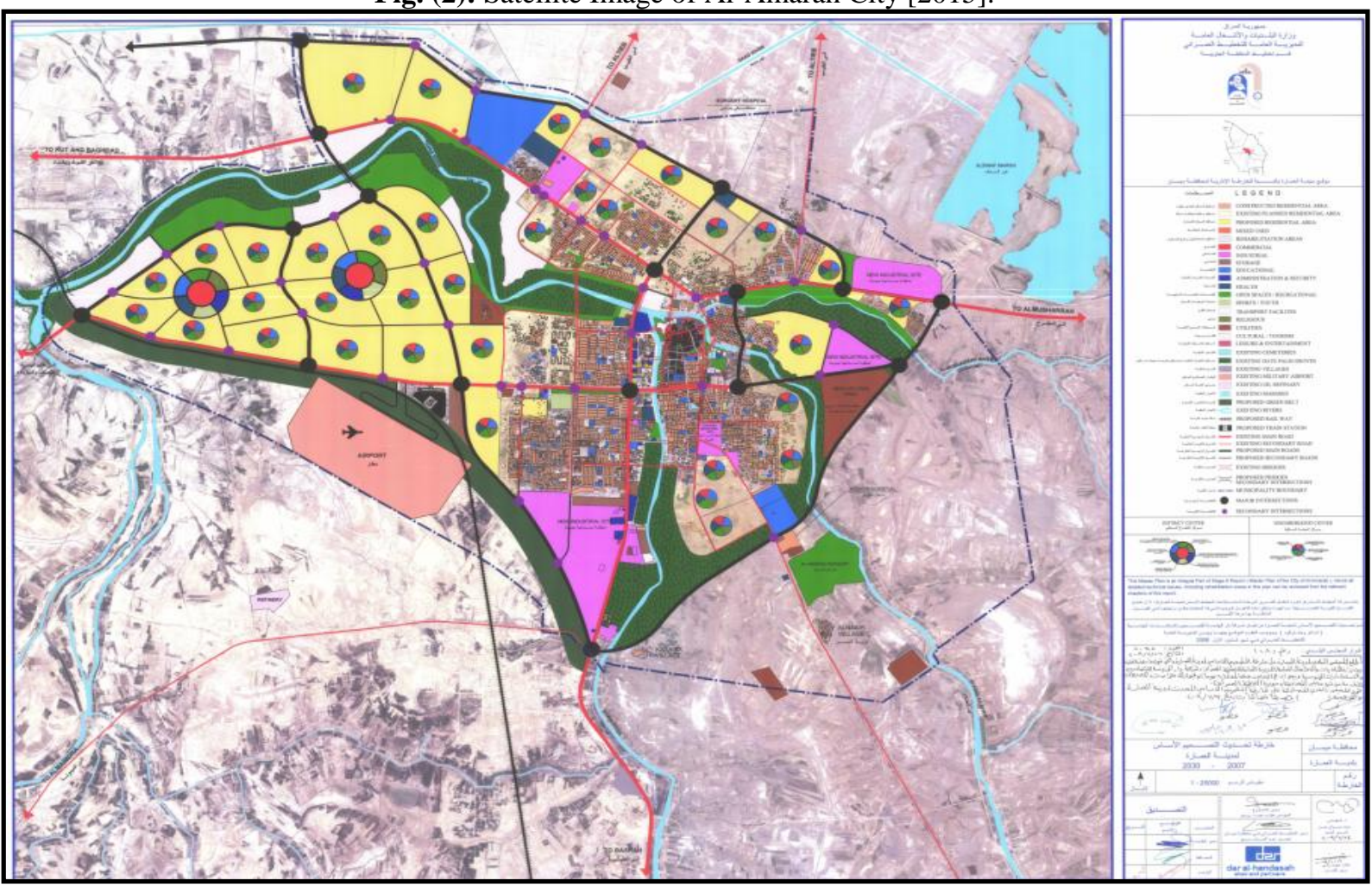

Fig. (3): Master Plan Map of Al-Amarah City (Directorate of AL-Amarah City Municipality) 


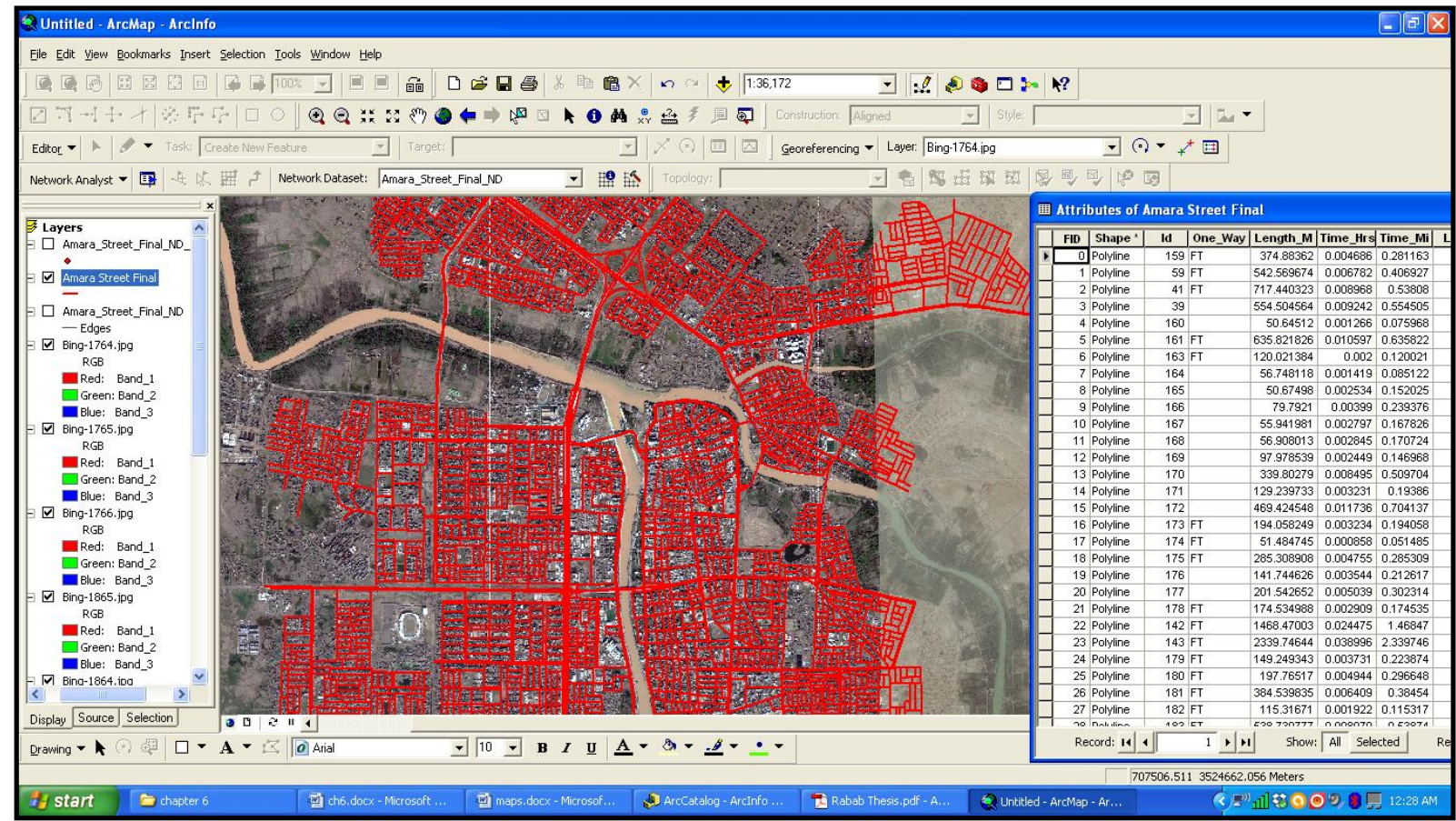

Fig.(4): Layer of Links of Al-Amarah Road Network

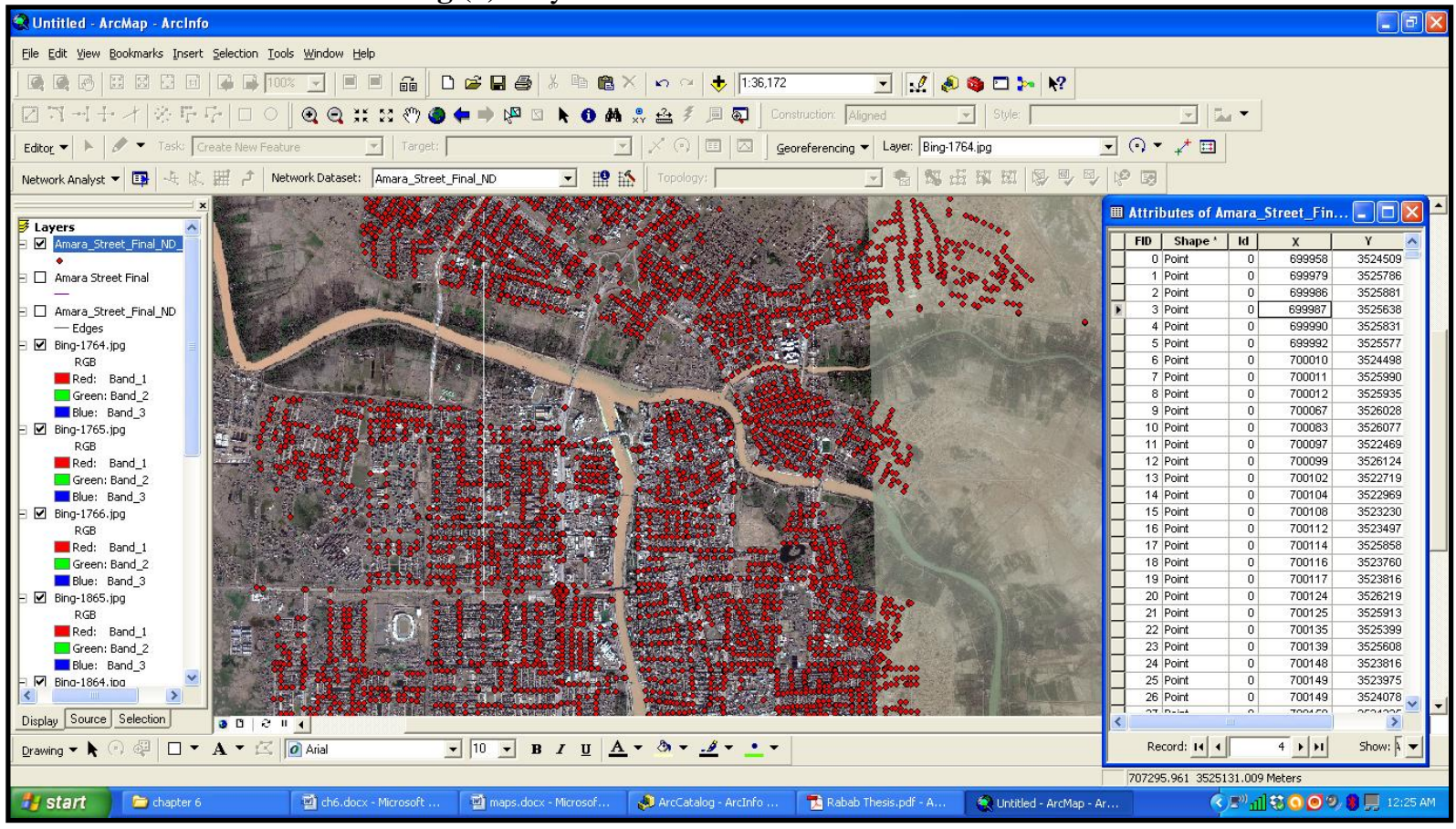

Fig. (5): Layer of Nodes and Intersections of Al-Amarah Road Network

\section{DATA BASE OF ROAD NETWORK}

After collecting the database for each shape file, that data was inserted and was organized by Arc GIS 10.3 program for connecting with these layers to execute the spatial network analysis.

\subsection{Data Base Of Links Shape}

The database of Al-Amarah road network was taken from the Directorate of AL-Amarah
Municipality (GIS unit and master plan map) while the others are obtained by observation or measuring them manually or by video recording. Mainly three types of attribute data were collected. The First data were descriptions attributes, which give the descriptions like roads (length, width, number of lane, speed limit, and capacity etc.), the second data was cost attributes, which play the essential role in the analysis of 
road to found the optimal route location, the cost of length of road in meters and cost of time (drive time) in minutes. Finally, third was the restriction attributes, which also have the main role accompanying cost attributes. This attribute data include restriction values like one-way and no entry road (closed road). Table (1) shows part of these attributes.

Table (1): Part of Data Set of Links Attributes

\begin{tabular}{ccccccccc}
\hline ID & $\begin{array}{c}\text { Link } \\
\text { Id }\end{array}$ & $\begin{array}{c}\text { One } \\
\text { Way }\end{array}$ & $\begin{array}{c}\text { Length } \\
(\mathbf{m})\end{array}$ & $\begin{array}{c}\text { Time } \\
(\mathbf{m i n})\end{array}$ & $\begin{array}{c}\text { Speed } \\
(\mathbf{k m} / \mathbf{h r})\end{array}$ & $\begin{array}{c}\text { Link width } \\
(\mathbf{m})\end{array}$ & $\begin{array}{c}\text { Capacity } \\
(\mathbf{p c p h})\end{array}$ & Dir. \\
\hline 1 & 237 & FT & 745.037 & 0.559 & 80 & 12 & 5130 & 1 \\
\hline 2 & 51 & FT & 743.828 & 0.558 & 80 & 12 & 4005 & 1 \\
\hline 3 & 30 & FT & 717.440 & 0.538 & 80 & 12 & 4005 & 1 \\
\hline 4 & 29 & & 554.505 & 0.555 & 60 & 12 & 5130 & 0 \\
\hline 5 & 184 & & 560.140 & 0.840 & 40 & 15 & 4160 & 0 \\
\hline 6 & 585 & FT & 635.822 & 0.636 & 60 & 10 & 3200 & 1 \\
\hline 7 & 577 & FT & 621.982 & 0.622 & 60 & 10 & 3200 & 1 \\
\hline 8 & 180 & & 555.277 & 0.833 & 40 & 15 & 4160 & 0 \\
\hline 9 & 182 & & 530.114 & 1.590 & 20 & 10 & 2050 & 0 \\
\hline 10 & 200 & & 729.253 & 1.094 & 40 & 15 & 4160 & 0 \\
\hline
\end{tabular}

\subsection{Data Base Of Nodes Shape File}

The database of nodes layer contained the number and the geographic coordinate of node (longitude and latitude) was obtained from the satellite image of Al-Amarah city. Example of these attribute is stated in Table (2), these were inserted in the attributed table of nodes layer. The attribute of nodes is necessary in spatial network analysis and traffic assignment of road network for the study area.

Table (2) Part of Nodes and Intersections Attributes.

\begin{tabular}{|c|c|c|c|}
\hline Id & Node Id & Longitude (m) & Latitude (m) \\
\hline 1 & 11 & 699957 & 3524497 \\
\hline 2 & 35 & 699958 & 3524509 \\
\hline 3 & 65 & 700345 & 3522038 \\
\hline 4 & 234 & 700347 & 3522059 \\
\hline 5 & 225 & 700359 & 3522639 \\
\hline 6 & 501 & 700365 & 3522058 \\
\hline 7 & 188 & 700366 & 3522038 \\
\hline 8 & 312 & 700370 & 3523181 \\
\hline 9 & 355 & 700370 & 3523201 \\
\hline 10 & 89 & 700375 & 3522639 \\
\hline
\end{tabular}




\subsection{Data Base Of Zone Shape File}

The database of the zones that was inserted in the attribute table of zones layer contained; the number of zones, land use of zone, zone area and population, and the socioeconomic characteristics of each zone as shown in Table (3). These were taken from the master plan map of Al-Amarah city and Directorate of AL-Amarah Statistics. In addition to the questioner forms that has been used in the trip generation step in order to collect the socioeconomic characteristics of each zone.

Table (3) Part of Zones Attributes.

\begin{tabular}{|c|c|c|c|c|c|c|c|c|c|c|c|}
\hline \multirow[t]{2}{*}{ Sectors } & \multirow{2}{*}{$\begin{array}{c}\text { No. of } \\
\text { Sub } \\
\text { TAZ }\end{array}$} & \multirow[t]{2}{*}{ Land use } & \multirow{2}{*}{$\begin{array}{l}\text { Area } \\
\left(\mathrm{km}^{2}\right)\end{array}$} & \multirow[t]{2}{*}{ Population } & \multicolumn{3}{|c|}{ Gender (\%) } & \multirow[b]{2}{*}{$6-18$} & \multirow[b]{2}{*}{$18-25$} & \multicolumn{2}{|c|}{ Age Group (\%) } \\
\hline & & & & & Female & Male & $<6$ & & & $\begin{array}{l}25- \\
60 \\
\end{array}$ & $>60$ \\
\hline 1 & $\begin{array}{c}44 \\
\text { zones }\end{array}$ & $\begin{array}{l}\text { Residential and } \\
\text { industrial }\end{array}$ & 15.2 & 116414 & 48.29 & 51.71 & 10.7 & 30.8 & 16.8 & 37.2 & 4.5 \\
\hline 2 & $\begin{array}{c}15 \\
\text { zones }\end{array}$ & $\begin{array}{c}\text { CBD } \\
\text { of the study area }\end{array}$ & 7.3 & 57409 & 45.01 & 54.99 & 13 & 29.5 & 16.2 & 36.8 & 4.5 \\
\hline 3 & 5 zones & Residential & 2.5 & 22227 & 48.26 & 51.74 & 12.6 & 29.9 & 16.6 & 36.6 & 4.3 \\
\hline 4 & $\begin{array}{c}21 \\
\text { zones }\end{array}$ & $\begin{array}{l}\text { Residential and } \\
\text { industrial }\end{array}$ & 8.6 & 129308 & 44.96 & 55.04 & 11.4 & 30.8 & 16.9 & 36.4 & 4.5 \\
\hline 5 & $\begin{array}{c}28 \\
\text { zones }\end{array}$ & $\begin{array}{l}\text { Residential and } \\
\text { educational }\end{array}$ & 10.3 & 117704 & 47.56 & 52.44 & 10 & 30.8 & 17.5 & 37.2 & 4.5 \\
\hline
\end{tabular}

\section{TRAFFIC ASSIGNMENT MODELS}

There are seven traffic assignment models available in the TransCAD software ver. 4.5, each of them are encountered in transportation planning practices. These models are:

1- All-or-Nothing Model.

2- STOCH Model.

3- Capacity Restraint Model.
4- Incremental Model.

5- User Equilibrium Model.

6- Stochastic User Equilibrium Model.

7- System Optimum Model.

Table (4) presents a brief description of these different models to understand the conceptual differences between algorithms and what applications they might be useful in this study.

Table (4): Traffic Assignment Models Algorithm Summary

\begin{tabular}{|c|c|c|c|c|c|}
\hline $\begin{array}{l}\text { Assignment } \\
\text { Method }\end{array}$ & $\begin{array}{l}\text { Assignment } \\
\text { Methodology }\end{array}$ & Iterative & Convergent & $\begin{array}{l}\text { Required } \\
\text { Network } \\
\text { Attributes }\end{array}$ & $\begin{array}{l}\text { Required } \\
\text { Algorithm } \\
\text { Settings }\end{array}$ \\
\hline $\begin{array}{l}\text { All-or- } \\
\text { Nothing }\end{array}$ & $\begin{array}{l}\text { All flows assigned } \\
\text { to least costly route }\end{array}$ & No & No & Time & None \\
\hline STOCH & $\begin{array}{l}\text { All flows assigned } \\
\text { to least costly route } \\
\text { (systematic error } \\
\text { introduced) }\end{array}$ & No & No & Time & Theta \\
\hline $\begin{array}{l}\text { Capacity } \\
\text { Restraint }\end{array}$ & $\begin{array}{c}\text { Repeated All-or- } \\
\text { Nothing assignments. } \\
\text { Link speeds updated } \\
\text { each iteration. }\end{array}$ & Yes & No & $\begin{array}{c}\text { Time } \\
\text { Capacity }\end{array}$ & $\begin{array}{c}\text { Iterations } \\
\text { Convergence } \\
\text { Alpha } \\
\text { Beta }\end{array}$ \\
\hline Incremental & $\begin{array}{l}\text { Small fraction of total } \\
\text { flow assigned per } \\
\text { iteration. } \\
\text { Link speeds updated }\end{array}$ & Yes & No & $\begin{array}{c}\text { Time } \\
\text { Capacity }\end{array}$ & $\begin{array}{c}\text { Iterations } \\
\text { Convergence } \\
\text { Alpha } \\
\text { Beta }\end{array}$ \\
\hline
\end{tabular}




\begin{tabular}{|c|c|c|c|c|c|}
\hline & each iteration & & & & \\
\hline $\begin{array}{c}\text { User } \\
\text { Equilibrium }\end{array}$ & $\begin{array}{c}\text { Mathematical } \\
\text { minimization of } \\
\text { Individual user's travel } \\
\text { time. }\end{array}$ & Yes & Yes & $\begin{array}{c}\text { Time } \\
\text { Capacity }\end{array}$ & $\begin{array}{c}\text { Iterations } \\
\text { Convergence } \\
\text { Alpha } \\
\text { Beta } \\
\end{array}$ \\
\hline $\begin{array}{l}\text { Stochastic } \\
\text { User } \\
\text { Equilibrium }\end{array}$ & $\begin{array}{c}\text { Mathematical } \\
\text { minimization of } \\
\text { Individual user's travel } \\
\text { time (systematic error } \\
\text { introduced). }\end{array}$ & Yes & Yes & $\begin{array}{c}\text { Time } \\
\text { Capacity }\end{array}$ & $\begin{array}{c}\text { Iterations } \\
\text { Convergence } \\
\text { Alpha, Beta } \\
\text { Function Error }\end{array}$ \\
\hline $\begin{array}{l}\text { System } \\
\text { Optimum }\end{array}$ & $\begin{array}{c}\text { Mathematical } \\
\text { minimization of total } \\
\text { system travel time. }\end{array}$ & Yes & Yes & $\begin{array}{c}\text { Time } \\
\text { Capacity }\end{array}$ & $\begin{array}{c}\text { Iterations } \\
\text { Convergence } \\
\text { Alpha } \\
\text { Beta }\end{array}$ \\
\hline
\end{tabular}

Stochastic User-equilibrium and System Optimum Models has been used for traffic assignment in this study for the following reasons.

1- Stochastic User Equilibrium (SUE) assignment is very similar to the UE assignment except that each traveler is not assumed to have perfect information. An error term is introduced to allow the algorithm to assign trips to less than optimal routes in an attempt to model how travelers make route decision 'errors'. The results of this assignment method are similar to the UE assignment except that certain less attractive routes will have small flow counts whereas they would have zero in the UE assignment.

2- The System Optimum assignment assigns trips to the network so that the total travel time for all trips in a network is minimized. In this assignment method, individual travel times are not minimized (as in the UE and SUE assignments), only the total travel time. Individual users may be able to choose alternate routes to reduce their own travel time but only at the cost of increasing the travel times of other travelers by a greater amount and thus the total system travel time. Ultimately, the System Optimum yields a solution whereby congestion is minimized.

\subsection{INPUTS REQUIRED IN TRAFFIC ASSIGNMENTS}

Traffic assignments in TransCAD ver. 4.5 require two main inputs:

1- Road network file.

2- Origin-destination, or 'demand', O-D matrix.

The following sections will more details about the road network and O-D matrix files used in these methods.

\subsubsection{ROAD NETWORK FILE}

A network file is a special data structure used by TransCAD software ver.4.5 to store the characteristics, attributes and spatial layout of a transportation system. This file is used in an array of transportation planning applications including traffic assignment but don't like the standard shape files and geographic files employed in most GIS based analysis.

Network file is created from the line and node layers that they are prepared using Arc GIS 10.3 program discussed previously. Figure (6) presents The Arc GIS line and node layers and their attribute tables used in the TransCad software ver. 4.5 to construct the network file.

At the time of creation the network file, it must be selected which attribute fields of the line and node layers will be stored in the network file. Every network file requires that its length be specified, but there are additional information required to be included in the network depending on the traffic assignment model are performing.

For the Stochastic User Equilibrium (SUE) and System Optimum Assignment (SOA) methods require data on both travel time and capacity for each link (street) must be included when creating the network File. Figure (7) shows the network dialog box creation. The data that is included in the creation of Al-Amarah city road network file are:

1- Link Id: presents the identified number (Id) of the link (street) in the network.

2-Length: represent the length of each link (street length) in the network measured in $[\mathrm{km}]$.

3- Width: presents the width of each link (street width based on the number of lane) in [m]. 4-Direction: represent the direction of flow on the link [0] for link flow in two directions, [1] for link flow in one direction].

5- Speed: represent the operating speed of vehicles on each link measured in $[\mathrm{Km} / \mathrm{h}]$. 
6- Travel Time: present the time required for vehicle to traverse the link measured in [min].

7- No. of Lane: present the number of lanes for each link in the network.

8- Capacity: represent the capacity of each link is calculated using the Highway Capacity Manual 2000 .
9- Volume: represent the external- external traffic volume in the network links.

$10-\alpha, \quad \beta$ : present volume /delay coefficients. Explain how severely increasing link flows affects link travel time. The program default values are used

the

$(0.15$,

$4.0)$.
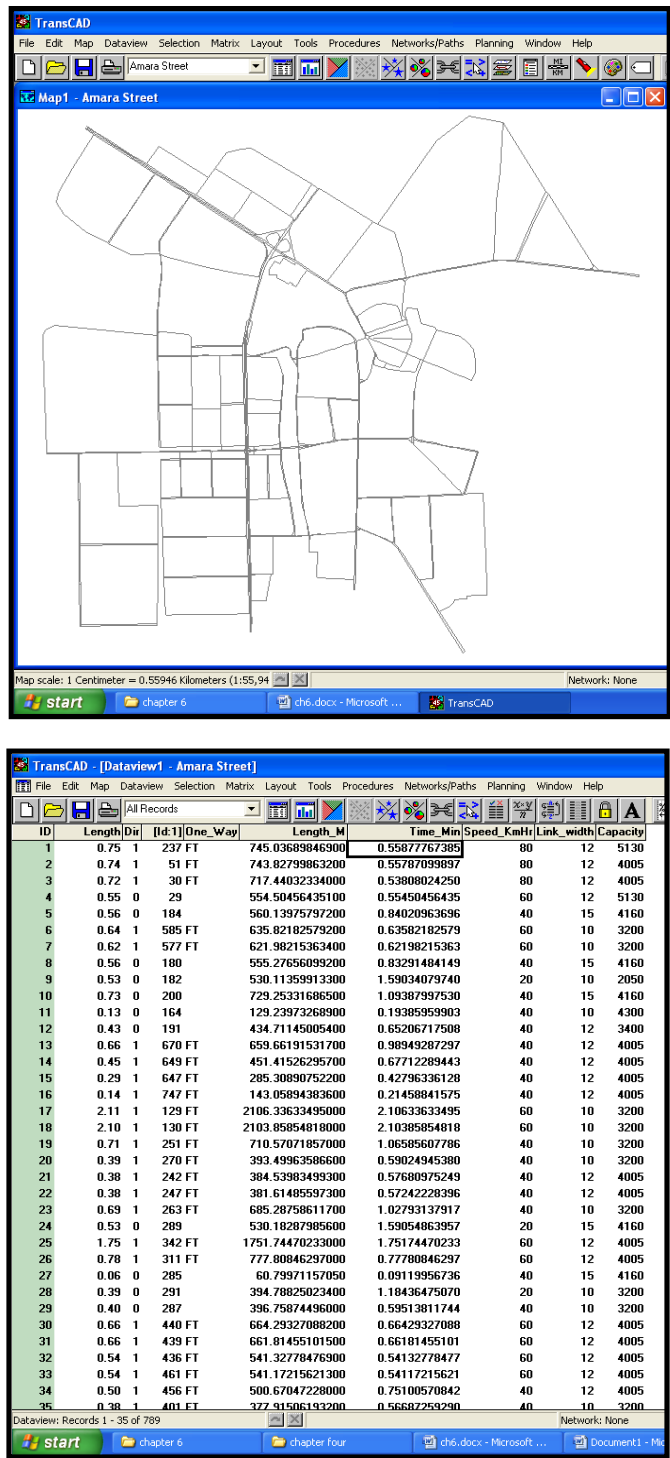
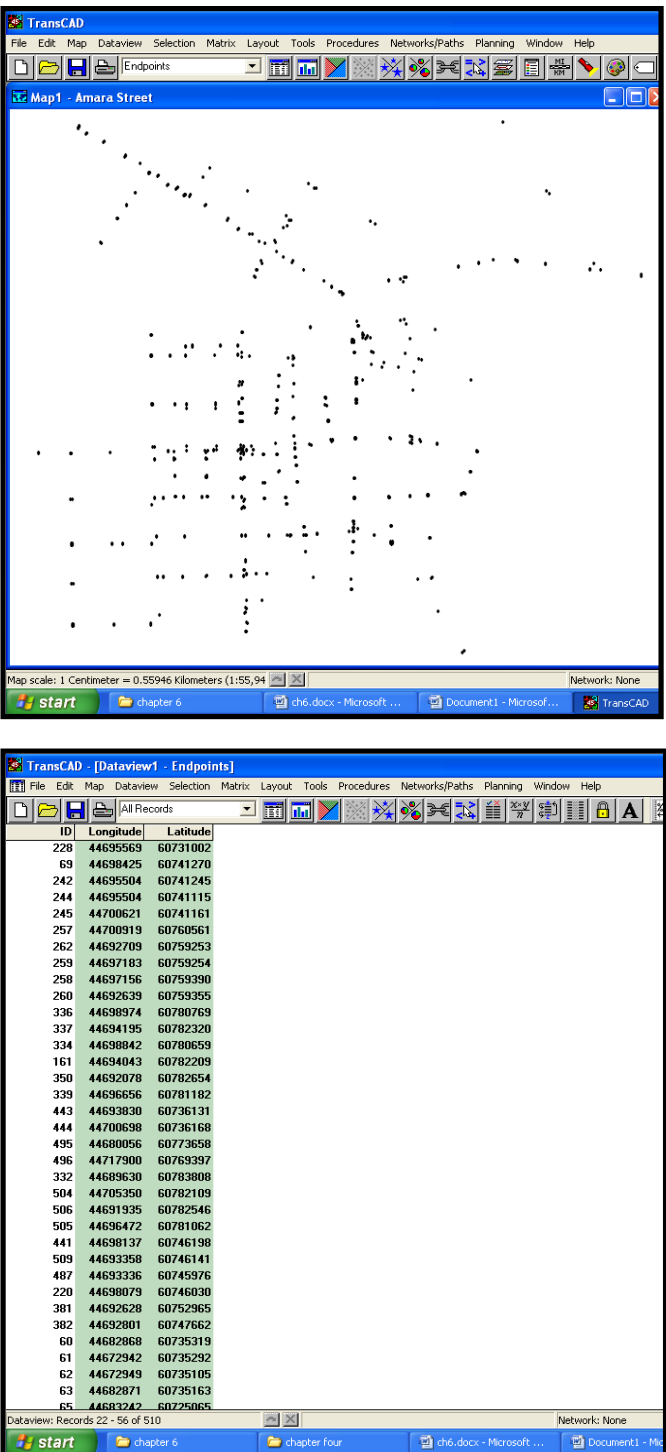

Fig. (6): The Arc GIS Line and Node Layers and The Attribute Tables Used to Prepare a Network File. 


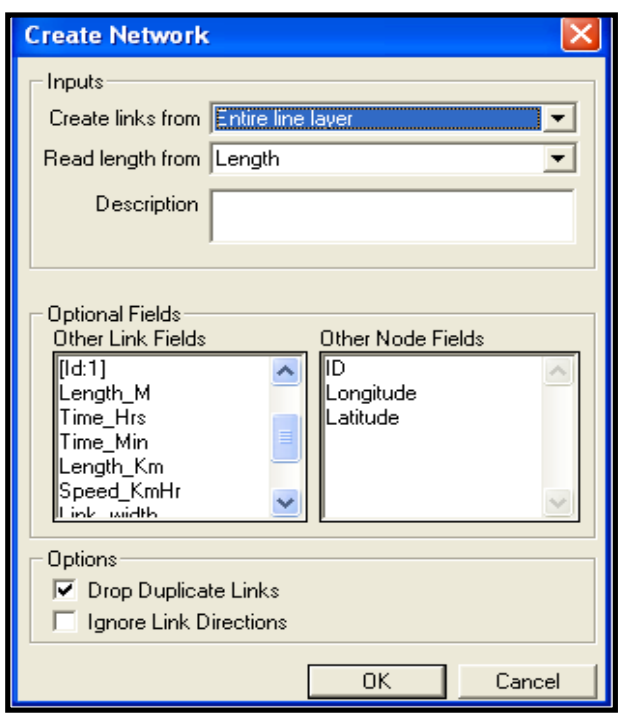

Fig. (7) Network Dialog Box Creation.

\subsubsection{Origin-Destination Matrix}

The O-D matrix is a convenient way of representing travel demand in a city or region. The matrix's rows and columns represent origin and destination locations respectively. Figure (8) showed the sectors of study area according to the division of the Municipality Directorate of ALAmarah city that represent the origin and destination locations.

All traffic assignment models included in TransCAD software ver.4.5 requires that travel demand be represented as an O-D matrix. Most O$\mathrm{D}$ matrices are based on a system of zones with each zone being considered a single possible origin and destination. TransCAD software ver4.5 can't able to modeling the traffic flows unless all trips begin and end their journey at some discrete point in the city network. To overcome this problem, centroids and centroid connectors are often employed.

A centroid is the geographic center of a zone. Since centroids will not be connected to the road network, a new set of links, call centroid connectors, are created to form the connection. TransCAD software ver. 4.5 can automatically connect any number of centroids to a network. Table (5) represents Al-Amarah peak hour O-D matrix (vph) by zone Id.

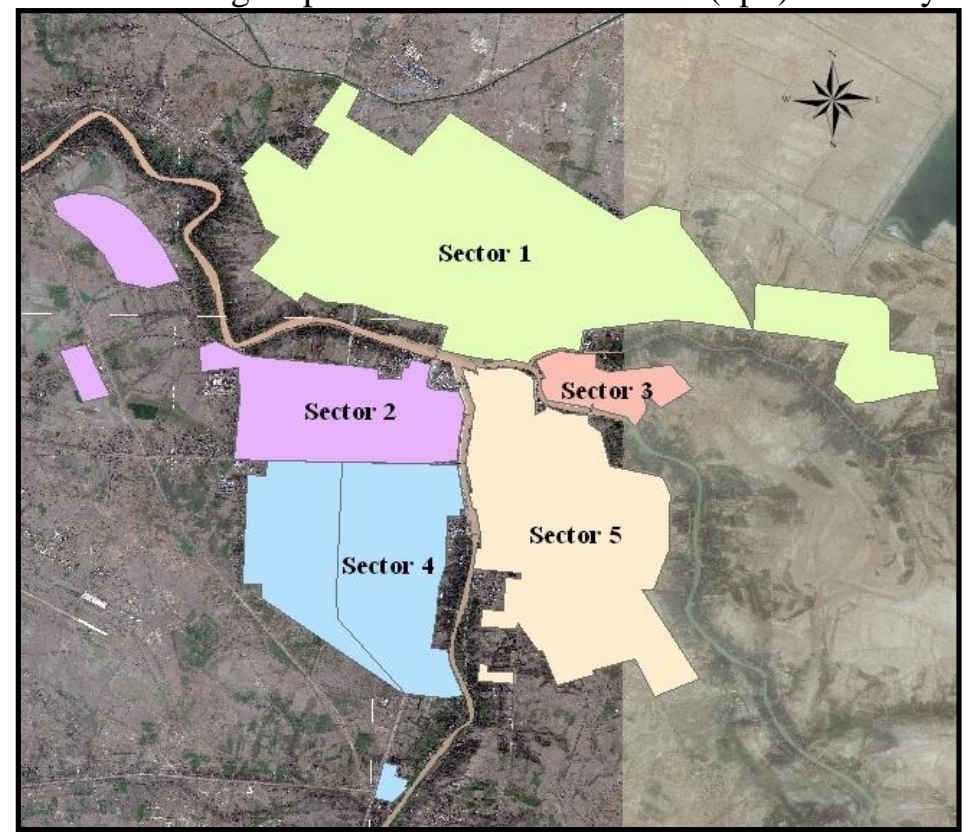

Fig.(8): Municipality Sector Divisions of the study area 
Table (5): Al-Amarah City Peak Hour O-D matrix (vph).

\begin{tabular}{ccccccc}
\hline Zone ID & $\mathbf{1}$ & $\mathbf{2}$ & $\mathbf{3}$ & $\mathbf{4}$ & $\mathbf{5}$ & $\sum \mathbf{O}_{i}$ \\
\hline 1 & 0 & 8748 & 6619 & 7502 & 6702 & 29571 \\
\hline 2 & 9750 & 0 & 4225 & 4555 & 6764 & 25294 \\
\hline 3 & 7630 & 4320 & 0 & 2805 & 4641 & 19396 \\
\hline 4 & 9470 & 9500 & 2705 & 0 & 4950 & 26625 \\
\hline 5 & 6688 & 3640 & 1643 & 4853 & 0 & 16824 \\
\hline$\Sigma D_{i}$ & 33538 & 26208 & 15192 & 19715 & 23057 & 117710 \\
\hline
\end{tabular}

\subsubsection{External-External Traffic Volume}

In order to complete the data required for performing the traffic assignment model, the external- external traffic volume must be allocated on the road network links. Figure (9) represented the locations of external zones for the study area. The External-External trips distribution between external zones is accomplished according to
NCHRP report 365. The final matrix is estimated based on the balanced E-E trip matrix resulting from Fratar balance process. The balance peak hour E-E trips per vehicle is presented in the Table (6). The peak hour O-D and E-E matrices are combined into one matrix that is used in traffic assignment

process.

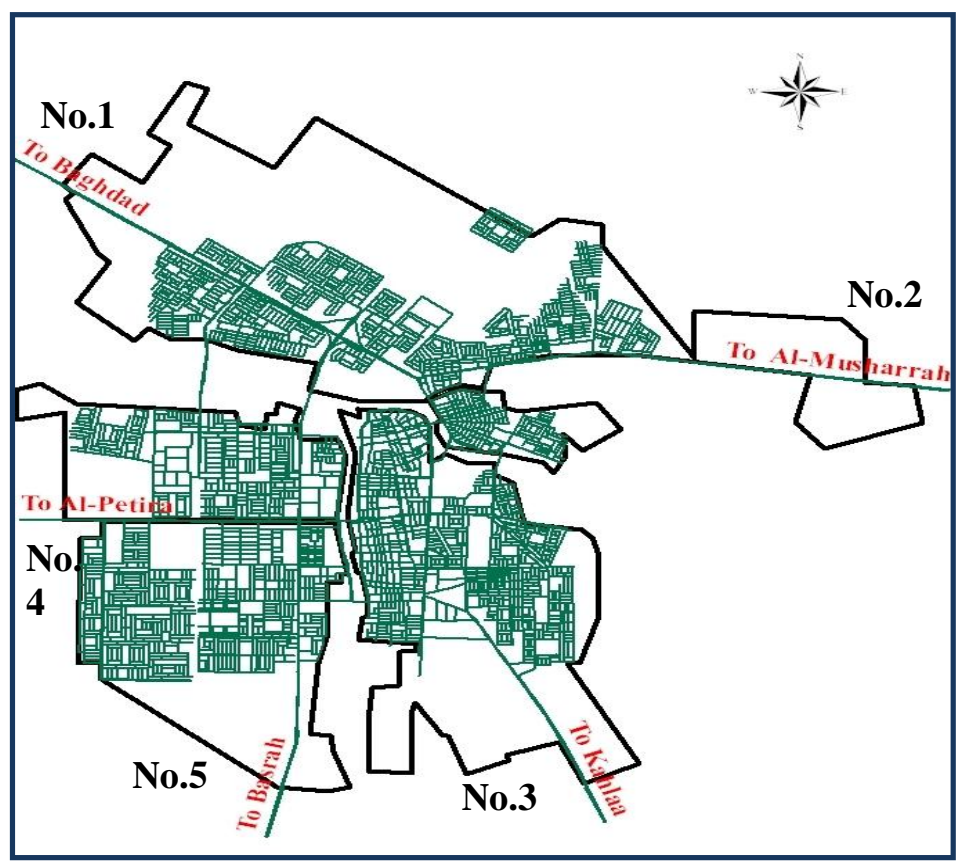

Fig. (9): Locations of External Zones 
Table (6): Al-Amarah City Peak Hour E-E Matrix (vph).

\begin{tabular}{ccccccc}
\hline Zone ID & $\mathbf{1}$ & $\mathbf{2}$ & $\mathbf{3}$ & $\mathbf{4}$ & $\mathbf{5}$ & $\sum \mathbf{O}_{i}$ \\
\hline 1 & 0 & 80 & 57 & 93 & 495 & 725 \\
\hline 2 & 72 & 0 & 26 & 25 & 75 & 198 \\
\hline 3 & 48 & 28 & 0 & 21 & 80 & 177 \\
\hline 4 & 84 & 28 & 23 & 0 & 18 & 501 \\
\hline 5 & 415 & 35 & 28 & 23 & 0 & 1754 \\
\hline
\end{tabular}

\subsubsection{Performing A Traffic Assignment}

Executing traffic assignments is simple in TransCAD software ver. 4.5. It is preparing the O-D matrix and network files with all the right data included as discussed in previous sections. TransCAD Stochastic User Equilibrium and System Optimum models are utilized for each assignment with a default number of iterations equal 20 per assignment. After each assignment, the output volumes for each link are exported to a new geographic file.

Table (7) presents Stochastic User Equilibrium and System Optimum methods settings are set at the time the assignment process is performed (Haider M. and Gregoul B., 2009).
Trips for each O-D pair are then assigned to the links in the minimum path and the trips are added up for each link. The assigned trip volume is then compared to the capacity of the link to see if it is congested. If a link is congested the travel time is adjusted to result in a longer travel time on that link. Changes in travel time means that the shortest path may change. The whole process is repeated several times (iterated) until there is an equilibrium between travel demand and travel supply. Trips on congested links will be shifted to uncongested links until this equilibrium, condition occurs. TransCAD automatically joins the results table to the attribute table of the street network file and shows this as a new data view on screen. Table (8) represents the level of service (v/c) ratio used in Al-Amarah city model.

Table (7): Stochastic User Equilibrium and System Optimum Models Settings

\begin{tabular}{|c|c|c|c|}
\hline \multirow[t]{2}{*}{$\begin{array}{l}\text { Algorithm } \\
\text { Settings }\end{array}$} & \multirow[t]{2}{*}{ Description } & \multicolumn{2}{|c|}{$\begin{array}{c}\text { Assignment Method Default } \\
\text { Value }\end{array}$} \\
\hline & & SUE & $\begin{array}{l}\text { System } \\
\text { Optimum }\end{array}$ \\
\hline Iterations & The maximum number of iterations to be performed & 20 & 20 \\
\hline Convergence & $\begin{array}{l}\text { The convergence threshold: If the maximum change in all the } \\
\text { link flows is less than this value, the traffic assignment } \\
\text { procedure will end even if the maximum number of iterations } \\
\text { has not been performed. }\end{array}$ & 0.0100 & 0.0100 \\
\hline $\begin{array}{l}\text { Alpha and } \\
\text { Beta }\end{array}$ & Calibration parameters of the volume-delay function. & $\begin{array}{l}\alpha=0.15 \\
\beta=4.0\end{array}$ & $\begin{array}{l}\alpha=0.15 \\
\beta=4.0\end{array}$ \\
\hline Function & $\begin{array}{l}\text { The type of error function used in the Stochastic User } \\
\text { Equilibrium assignment }\end{array}$ & Normal & - \\
\hline Error & $\begin{array}{l}\text { Describes the extent to which the error function employed in the } \\
\text { Stochastic User Equilibrium assignment }\end{array}$ & 5.000 & - \\
\hline
\end{tabular}


Table (8): Level of Service (v/c) Ratio (Lima and Associates, 2006).

\begin{tabular}{cc}
\hline Level of Service & (V/C) Ratio \\
\hline A & $0.00-0.50$ \\
\hline B & $0.51-0.70$ \\
\hline C & $0.71-0.80$ \\
\hline D & $0.81-0.90$ \\
\hline E & $0.91-0.99$ \\
\hline F & $\geq 1$ \\
\hline
\end{tabular}

The results of the stochastic user equilibrium assignment model and the system optimum assignment model are presented in the Figure (10) and Figure (11) respectively.

From Figure (10) it can be notice that: the v/c ratio is divided into ten classes. The links with green color present most of Al-Amarah road network have $(\mathrm{v} / \mathrm{c})$ ratio range between $(0.00$ $0.50)$, level of service A. The yellow and orange colors represent the $\mathrm{v} / \mathrm{c}$ range between $(0.50-0.70)$ LOS B that is included links (223-224-374- 377433-514-647-648-681). The links with orange color present the range between $(0.70-0.80)$ LOS $\mathrm{C}$ are (35-167-188-189-370-449-472-517-544721-745). Finally there is no link in Al-Amarah network has $\mathrm{v} / \mathrm{c}$ ratio between the range $(0.81$ 1.00) and over which represent level of service equal to or more than $\mathrm{D}$. The overall evaluation of Al-Amarah road network is LOS equal to B.
From Figure (11) you can notice that: there are changes in the v/c ratio of many links in AlAmarah network from the result of stochastic user equilibrium assignment model. For example: the links with green color (41-42-383) which have v/c ratio equal to 0.269 (LOS A) is changed to yellow color and their $\mathrm{v} / \mathrm{c}$ ratio is increased to 0.537 (LOS B). While another links their v/c ratios decrease and their color change from dark orange (LOS C) to yellow or light orange like (35-188-189-681) with (LOSB). On the other hand links with green color that represents most of the network remains as in the previous assignment method. The $\mathrm{v} / \mathrm{c}$ ratio of links represent the bridges remains as previous method or do better like (647-648) and (370-721) with (LOS C). In general there is an improvement in the work of Al-Amarah road network by using the system optimum model. 


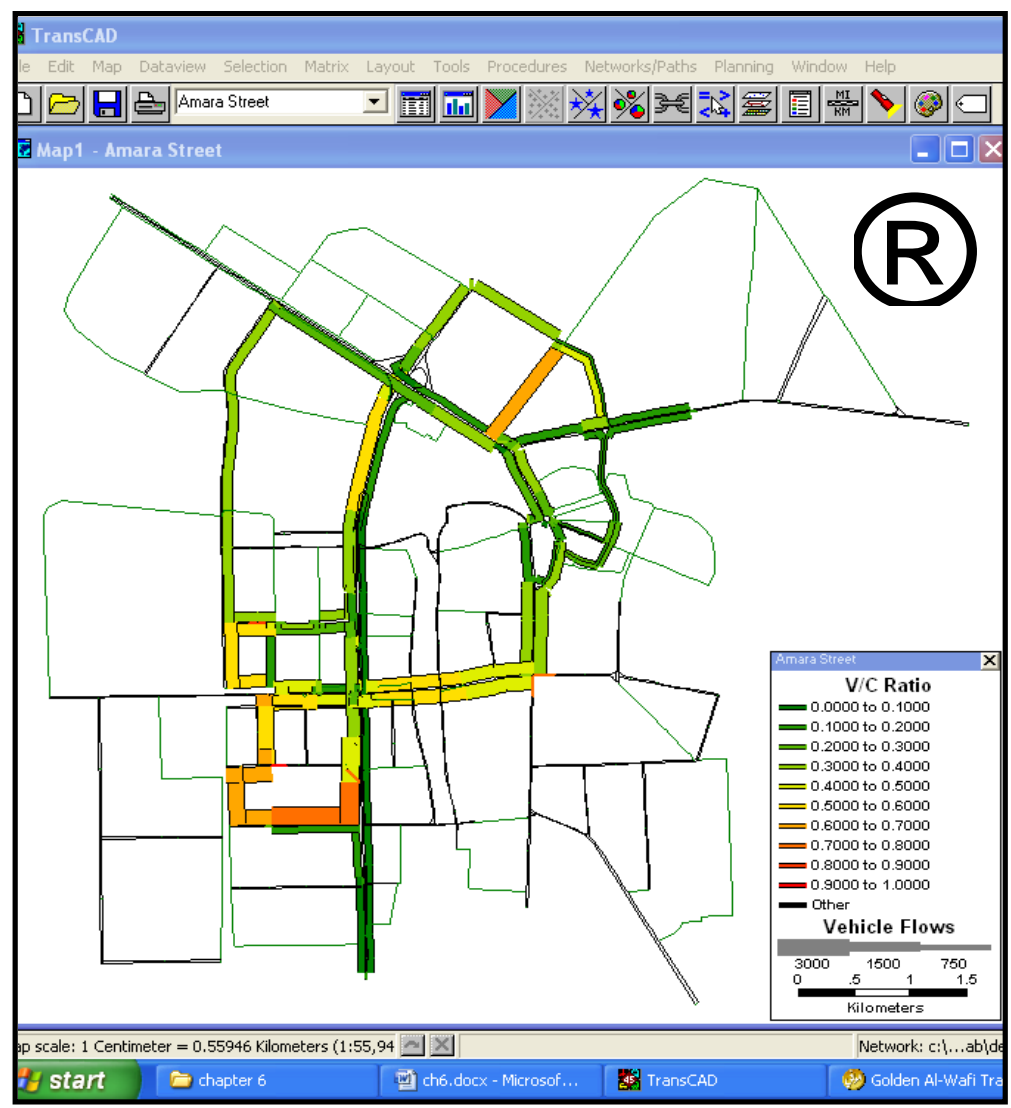

Fig. (10): Stochastic User Equilibrium Assignment Model Result

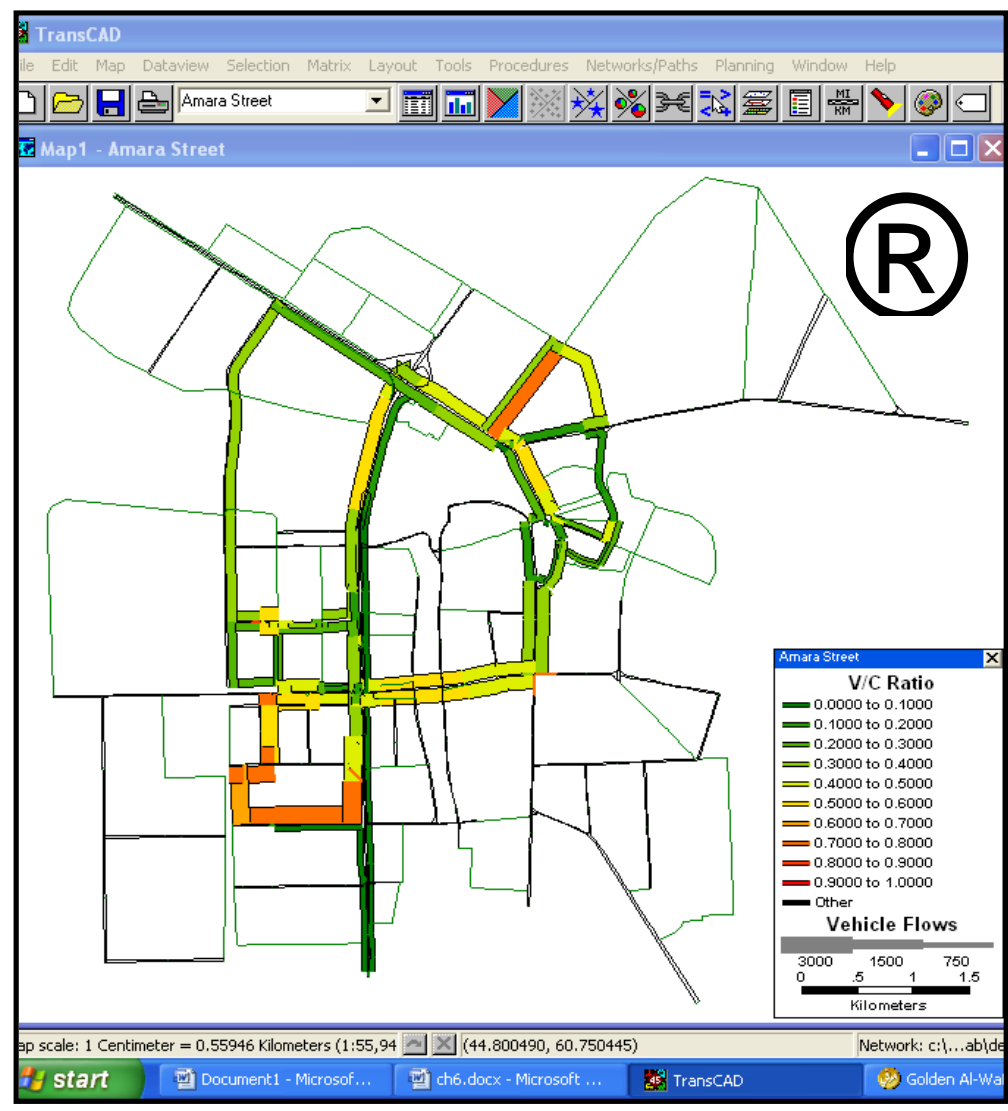

Fig.(11): Result of the System Optimum Assignment Model 


\subsubsection{Model Calibration}

Model calibration/validation is strictly an aggregate set of comparisons, and represents the final step in the model development process. The comparison of the applied model in the base year with the observed data serves to indicate how well the model is replicating the existing travel patterns. The percent difference between modeled volumes and actual counts may be large, but is only significant in relation to its functional classification and the magnitude of the volume itself (Lima and Associates, 2006).
The percent error of traffic assignment has been used as performance measure to indicate the accuracy with which the two assignment models replicate the actual traffic counts. Percent error is the difference between the assigned traffic volume and the counted traffic volumes divided by the counted traffic volumes. Table (9) presents the percent error by functional classification for Stochastic User Equilibrium and System Optimum assignment

Table (9): Percent Error by Functional Classification of Stochastic User Equilibrium and System Optimum Assignment Models.

\begin{tabular}{|c|c|c|c|c|c|c|}
\hline $\begin{array}{c}\text { Functional } \\
\text { class }\end{array}$ & $\begin{array}{l}\text { Sum of } \\
\text { Counts }\end{array}$ & $\begin{array}{l}\text { Sum of O.S } \\
\text { Assign model }\end{array}$ & $\begin{array}{c}\text { Percent of } \\
\text { Error (\%) }\end{array}$ & $\begin{array}{l}\text { Sum of S.U.E } \\
\text { Assign model }\end{array}$ & $\begin{array}{l}\text { Percent of } \\
\text { Error (\%) }\end{array}$ & $\begin{array}{c}\text { Percent of } \\
\text { Target Error * }\end{array}$ \\
\hline Collector & 215221 & 225321 & 4.69 & 221453 & 2.90 & $25 \%$ \\
\hline Major Collector & 90534 & 98323 & 8.60 & 95423 & 5.40 & $25 \%$ \\
\hline Minor Arterial & 436146 & 449019 & 2.95 & 441111 & 1.14 & $15 \%$ \\
\hline Major Arterial & 126337 & 129489 & 2.49 & 131547 & 4.12 & $10 \%$ \\
\hline Average & 868238 & 902152 & 3.91 & 889534 & 2.45 & $5 \%$ \\
\hline
\end{tabular}

* As sited in (Lima and Associates, 2006)

\subsubsection{Future Flow O_D Matrix}

The road network facilities are designed on the basis of the age of design (Design Life) and an annual increase of traffic volumes (Rate of Increase) in order to be economically viable and thereby ensure these facilities result the acceptable roles and the required tasks during the operational year's life.

In order to evaluate Al-Amarah city road network facilities and measure its ability to accommodate an annual increase in the traffic volume in target year [2035], the future traffic volumes (peak hour O-D matrix) and the future external-external trips are estimated based on the proportion of annual increase in traffic volumes of $4 \%$ according to the Directorate of Traffic of AlAmarah city.

Figure (12) and Figure (13) represent the result maps of the stochastic user equilibrium assignment model and the system optimum assignment model in the target year [2035].
From Figure (12) we can notice that: The black color $(\mathrm{v} / \mathrm{c}>1.0)$ is appeared clearly in the assignment result map in 19 links especially on the two main bridges in the city (Al-Yugoslavi Bridge and Al-Jumhuriah Bridge) with links Id (370-377-647-648). When the red color (LOS E) is appeared in twelve link in the network near the centers of zone (1,2, and 4). The most links ranges between (LOS D and LOS C) with v/c ratio Range (0.70-0.90).

From the figure, the result of optimum system model for the target year is almost similar to the result of stochastic user equilibrium model. There are few differences between two models for example; the (v/c) ratio of links (188-189-223) is increased more than (1.0) with (LOS F) and the level of service of links (69-70-100-220-435-628) is shifted from (LOS D) to (LOS E). While Links (40-42-140-343-366-382-383- 403-434-688-720) $\mathrm{v} / \mathrm{c}$ ratios are increased so that their level of service is decreases from (LOS B) to (LOS C). 


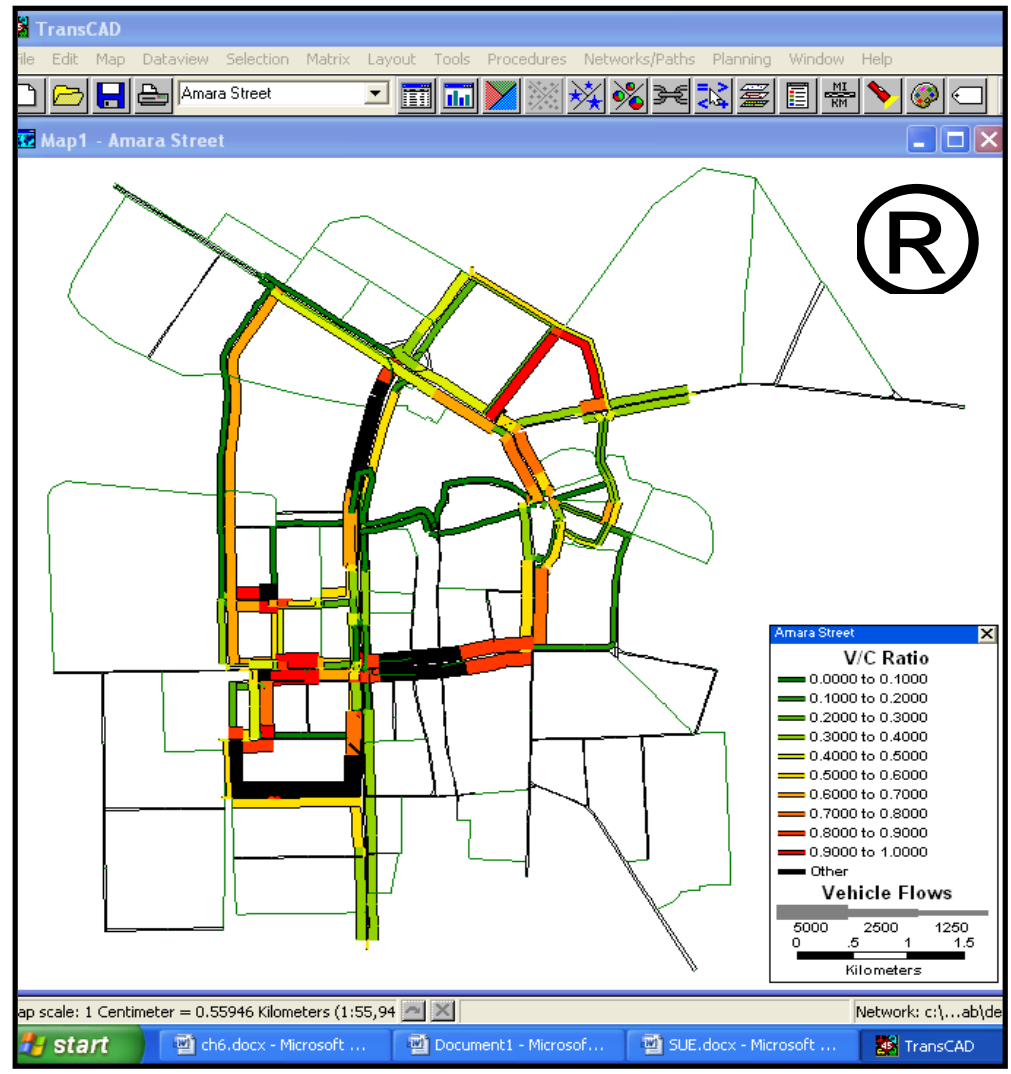

Fig. (12): Stochastic User Equilibrium Assignment Model Result for Target Year [2035].

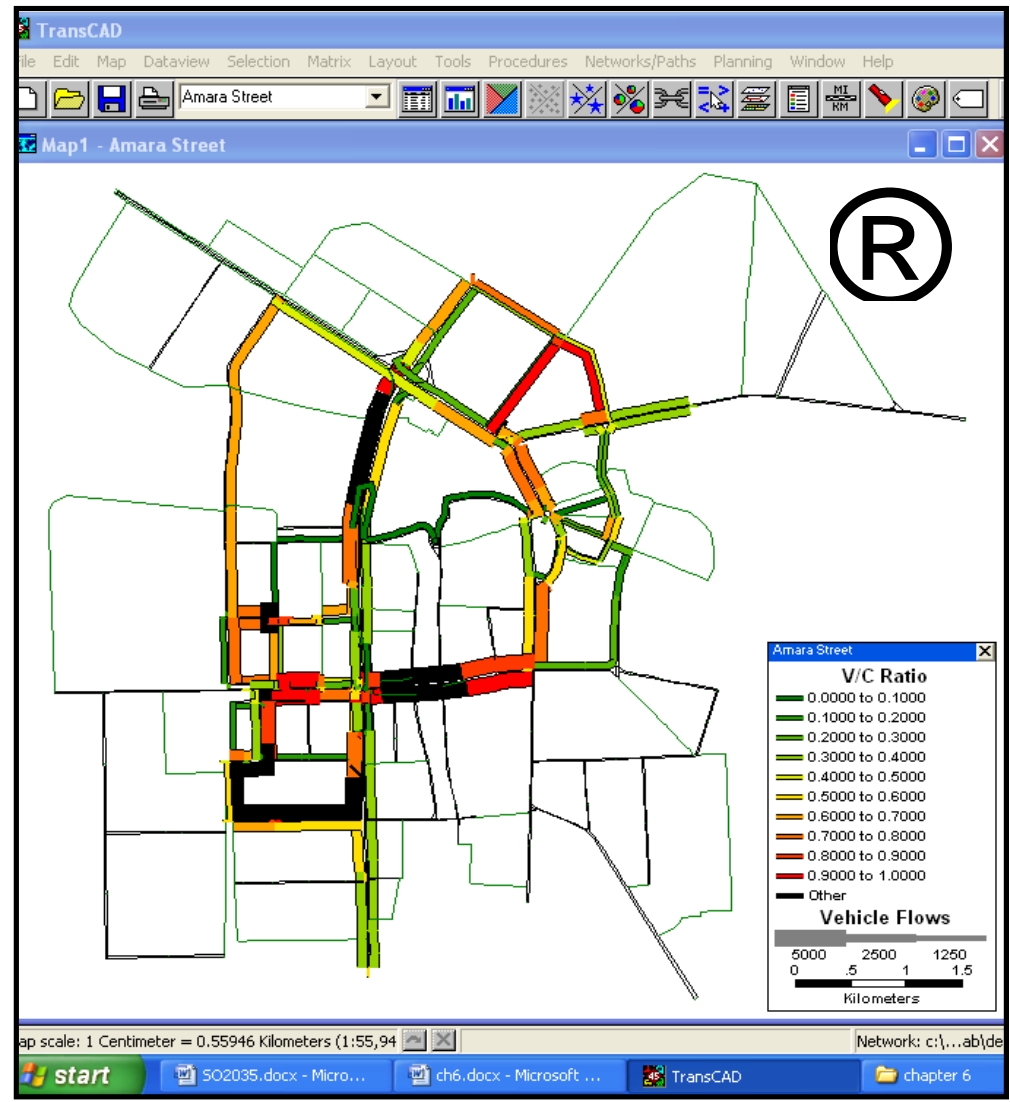

Fig. (13): Optimum System Assignment Model Result for Target Year [2035]. 


\section{CONCLUSIONS}

1. After applying the Stochastic User Equilibrium and Optimum System Assignment Models for assignment the traffic in Al-Amarah road network the results of two models nearly were convergent and there is a small improvement in the work of Al-Amarah road network by using the system optimum model.

2. The result of the two assignment models for the base year represents that:

- The links with green color present most of AlAmarah road network which, have $(\mathrm{V} / \mathrm{C})$ ratio range between (0.00-0.50), level of service $\mathrm{A}$.

- The yellow color represent the V/C range between $(0.50-0.70)$ LOS B and The links with orange color present the range between $(0.70$ 0.80) LOS C represent small number of links in the network that suffer of on street parking.

- Finally there is no link in Al-Amarah network has V/C ratio between the range (0.81-1.00) and over which represent level of service equal to or more than $\mathrm{D}$. The overall evaluation of AlAmarah road network is LOS equal to B.

3. The result of the two assignment models for the target year represents that: The black color (V/C $>1.0$ ) is appeared clearly in the assignment result map in nineteen link especially on the two main bridges in the city (Al-Yugoslavi Bridge and AlJumhuriah Bridge) when the red color (LOS E) is appeared in twelve link in the network near the centers of zone $(1,2,4)$. The most links ranges between (LOS D and LOS C) with V/C ratio Range (0.70-0.90).

\section{RECOMMENDATIONS}

An important product of the analysis is the development of a program which outlines the improvements to be carried out for the base and target year. From the assignment performed, the type of improvement required to the Al- Amarah road network to carry the existing and future traffic flow has been identified.

1-The external-external trips that pass through the network should be changed their path to AlAwfiagh arterial road as planned by the previous design study as first step and a ring road should be constructed to carry the external trips without pass through the center of the city.

2-In order to increase the capacity of congested links, on street parking and encroachment should be removed and the carriageway of these links should widened in addition to Traffic Management Measure is required.

3- New roads should be added to current network and new bridges on the rivers that cross and divide the road network should be constructed as the master plan suggested.

4- The city needs to establish a modern public transport system based on coordination with the General Directorate of Traffic in the city to identify new paths of movement in order to reduce traffic congestion and reduce travel time and costs.

\section{REFERENCES}

- Al-Jazzar, M., et al. (2013). TransCAD and GIS Technique for Estimating Travel Demand and its Application in Gaza City. Open Journal of Civil Enginerring.

- Desai T. A., et al. (2011). Transportation Planning Models: A Review. National Conference on Recent Trends in Engineering \& Technology 13-14 May 2011 B.V.M. Engineering College, V.V. Nagar, Gujarat, India.

- Garber, N.J., Hoel, L. A. (2010). Traffic and Highway Engineering. $4^{\text {th }}$ Edition, International Student Edition, Thomson, USA.

- Haider, M., Gregoul, B. (2009). Traffic Assignment Models (Draft) Travel Demand Models.

- Lima, and Associates, (2006). Lincoln MPO Travel Demand Model. Draft Model Documentation, Prepared for Lincoln Metropolitan Planning Organization, Transportation- G.I.S.

- Mandowara, N. P. and Zala, L. B. (2013). Traffic Assignment on Urban Road Network - a Case Study of Anand Agglomeration. Paripex- Indian Journal Of Research, Volume : 3 , Issue : 4 , ISSN - 2250-1991.

- Mathew, T. V. and Rao, K. V. (2007). Introduction to Transportation Engineering - Travel Demand Modeling. National Programming on Technology Enhanced Learning (NPTEL).

- MEMON, I. A. (2005). Application of Geographic Information System in Transportation for Road Network Analysis. MSc. thesis, Faculty of Civil Engineering, University Technology of Malaysia.

- Mohammad S. Ullah et. al. (2011). Travel Demand Modeling for The Small and Medium Sized MPOs in Illions. A report of the findings of ICT-R27-48, Travel Demand Modeling Technical Support Group, Illinois Center for Transportation. (FHWA).

- Qasim, G. J. (2016) . Travel Demand Modeling: AlAmarah City as a Case Study". PhD. thesis submitted to the Engineering College, University of Baghdad.

- TransCAD, Transportation Solutions in GIS. Caliper Corporation, www.caliper.com/tcovu.htm. 